Article

\title{
Biosynthesis and Biomedical Applications of Gold Nanoparticles Using Eclipta prostrata Leaf Extract
}

\author{
Govindasamy Rajakumar ${ }^{1}$, Thandapani Gomathi ${ }^{2}$, Abdul Abdul Rahuman ${ }^{3, *}$, \\ Muthu Thiruvengadam ${ }^{1}$, Govindarasu Mydhili ${ }^{4}$, Seung-Hyun Kim ${ }^{1}$, Tak-Jun Lee ${ }^{1}$ and \\ II-Min Chung ${ }^{1, *}$ \\ 1 Department of Applied Bioscience, College of Life and Environmental Science, Konkuk University, \\ Seoul 143 701, South Korea; microlabsraj@gmail.com (G.R.); thiruv30@yahoo.com (M.T.); \\ kshkim@konkuk.ac.kr (S.-H.K.); ltjnazi@konkuk.ac.kr (T.-J.L.) \\ 2 Department of Chemistry, D.K.M. College for Women, Vellore, Tamil Nadu 632001, India; \\ chemist.goms@gmail.com \\ 3 Unit of Nanotechnology and Bioactive Natural Products, Post Graduate and Research Department of \\ Zoology, C. Abdul Hakeem College, Melvisharam-632 509, Vellore District, Tamil Nadu, India \\ 4 Department of Biochemistry, Periyar University, Salem, Tamil Nadu 636011, India; mydhilibc12@gmail.com \\ * Correspondence: abdulrahuman6@hotmail.com (A.A.R.); imcim@konkuk.ac.kr (I.-M.C.); \\ Tel.: +91-9442-3101-55 (A.A.R.); +82-1054-7083-01 (I.-M.C.)
}

Academic Editor: Raed Abu-Reziq

Received: 17 June 2016; Accepted: 29 July 2016; Published: 9 August 2016

\begin{abstract}
This study reports the biological synthesis of gold nanoparticles (AuNPs) by the reduction of $\mathrm{HAuCl}_{4}$ by using of Eclipta prostrata leaf extract as the reducing and stabilizing agent. AuNPs were characterized using Ultraviolet-visible (UV-vis) spectroscopy, X-ray diffraction (XRD), Fourier Transform-Infrared (FTIR) spectroscopy, Scanning Electron Microscopy (SEM), High Resolution-Transmission Electron Microscopy (HRTEM), and Energy Dispersive X-ray analysis (EDAX). The UV-visible spectrum of the synthesized AuNPs showed surface plasmon resonance (SPR) around $534 \mathrm{~nm}$. The face-centered cubic (FCC) structure of the AuNPs was confirmed by XRD peaks at $38.10^{\circ}, 44.13^{\circ}, 64.43^{\circ}$, and $77.32^{\circ}$, which correspond to (111), (200), (220), and (311) miller indices, respectively, with clear circular spots in the selected area electron diffraction (SAED). FTIR measurements showed the AuNPs having a coating of phenolic compounds, indicating a possible role of biomolecules responsible for capping and efficient stabilization of the AuNPs. The HRTEM images determined the particles are spherical, hexagonal, and triangular in shape, with an average size of $31 \pm 1.6 \mathrm{~nm}$. The synthesized AuNPs show good antibacterial, antioxidant, and cytotoxic activity. The outcomes of this study indicate that these nanoparticles could be effectively utilized in pharmaceutical, biotechnological, and biomedical applications.
\end{abstract}

Keywords: gold nanoparticles; Eclipta prostrata; characterization; antibacterial activity; cytotoxic activity

\section{Introduction}

Metal nanoparticles are utilized not only in research but in many fields of applications, especially in the pharmaceutical and biomedical fields, owing to their improved physical and chemical properties upon size reduction. These particles have a broad range of applications, such as catalysis, biosensing, optoelectronics, chemical sensing, and medical diagnosis [1]. Out of various nano-structured materials under research, gold nanoparticles (AuNPs) are of particular interest to scientific community owing to their stability, inertness, and potential applications in biotechnology [2]. Additionally, AuNPs can efficiently bind to thiol and amine groups, which help with surface modification and increase their effectiveness in biomedical applications. Various physical and chemical processes have been involved in the synthesis of AuNPs. However, these processes generate a large amount of hazardous 
byproducts [3]. Hence, there has been a growing interest to make a remarkable improvement in the ability to synthesize AuNPs to overcome the disadvantages of the physical and chemical process. It is suggested that the use of plant materials for the synthesis of AuNPs could be more advantageous than the physical and chemical method. Several studies have shown that biomolecules like amino acids, organic acids, phenols, and flavonoids present in plants play a vital role in reducing the metal ions to their respective nanomaterials as well as aid in the capping of the metal NPs, which keeps them stable for a longer period. In addition to this, plant extracts are secure to handle, readily available, and have a wide variety of metabolites that may aid in the reduction of metal salts to NPs [4].

Application of nanotechnology to herbal drugs may lead to the development of nano herbal products possessing high bioavailability and less toxicity, which consequently will open a new era of herbal drug discovery [5]. Several plants were productively used for efficient and rapid extracellular production of stable dispersions of AuNPs. Apart from this, plant extracts used for the biosynthesis of gold nanoparticles have gained much more importance due to their simplicity, eco-friendliness, and non-toxic nature [6]. Recently, AuNPs were used for cancer cell detection, encapsulation of drugs, nerve cell signaling stimulator, luminescent biomarker, drug delivery, sensor analysis, and membrane filtration, and as nano barcodes, and antimicrobial agents [7]. Cancer is one of the most challenging diseases to cure and the second leading cause of death in developed countries. Over the past few decades, it continues to be a worldwide health problem despite the rising number of nanoscaled technologies [8]. The synthesis of AuNPs was mediated by an extract of Allium cepa and it was internalized by MCF-7 breast cancer cells via endocytosis [9]. AuNPs have recently been investigated for biocompatibility according to their interactions with human breast epithelial MCF-7 cells, which were assessed by cytotoxicity by MTT assay and caspase 3, 9, Bax, and Bcl expression by real-time PCR assays [10].

In addition, green synthesis of gold nanoparticles has been previously achieved using different parts of various plants like Ginkgo biloba [11], Nepenthes khasiana [12], Panax ginseng [13], Mentha piperita [14], Mappia foetida [15], Bambusa chungii [16], Ocimum santum [17], and Butea monosperma [18]; there are no reports of the biosynthesis of AuNPs using Eclipta prostrata.

Eclipta prostrata (Asteraceae) is a perennial herb distributed in the tropical and sub-tropical regions of the world. It is a common weed in moist regions throughout India. There is a potential for medicinal use of this plant as an antiseptic, stringent, depurative, emetic, febrifuge, ophthalmic, purgative, styptic, and tonic, for use against hepatitis, jaundice, liver cirrhosis, aching and weakness of the knees and loins, hematuria and diarrhea with bloody stools, and abnormal uterine bleeding [19]. Also, previous phytochemical studies on E. prostrata revealed the presence of thiophene-derivatives, steroids, triterpenes [20,21], flavonoids, polyacetylenes, polypeptides, coumestons, alkaloids, and so on, which are responsible for all its significant traditional medicine properties [22-24].

Since the plant extracts may act both as reducing agents and stabilizing agents in the synthesis of nanoparticles [25,26], in the present study, we report the synthesis of AuNPs by reduction of gold ions using E. prostrata extract. AuNPs were characterized with Ultraviolet-visible (UV-vis) spectroscopy, X-ray diffraction (XRD), Fourier Transform-Infrared (FTIR) spectroscopy, Scanning Electron Microscopy (SEM), and High Resolution-Transmission Electron Microscopy (HRTEM). Moreover, Au-NPs were screened for antibacterial, antioxidant (total antioxidant activity, determination of total phenolic contents, and determination of DPPH radical scavenging activity), and anticancer activities (MTT assay, Caspase-3, 8, 9 assays) against Hep-G2 cell lines. In the present study, we report the novel synthesis of AuNPs by reduction of gold ions using E. prostrata aqueous leaf extract. The biotechnological method, capable of producing AuNPs at room temperature and involving assisted template synthesis of AuNPs, is a green, high-yield, fast, and low-cost approach. In addition, the sizes of the particles produced by the one-step synthesis are large enough for the particles to be used in biological applications. 


\section{Materials and Methods}

\subsection{Materials}

Fresh and healthy E. prostrata leaves were collected, washed with deionized water, shade dried, and powdered. The $\mathrm{HAuCl}_{4}(99.9 \%)$ was obtained from Sigma-Aldrich (Bangalore, India), and all of the other chemicals were also purchased from Sigma-Aldrich and Hi-Media (Mumbai, India). Reagents were purely analytical grade and used without any further purification.

\subsection{Preparation of Plant Extract}

About $10 \mathrm{~g}$ of finely cut leaves were weighed and transferred into a $250-\mathrm{mL}$ beaker containing $100 \mathrm{~mL}$ distilled water, mixed well, and boiled for $15 \mathrm{~min}$. The extract obtained was filtered through Whatman No.1 filter paper and the filtrate was collected in a 250-mL Erlenmeyer flask and stored in the refrigerator for further use [27].

\subsection{Biosynthesis of Gold Nanoparticles (AuNPs)}

An aqueous solution of HAuCl4 $(1.0 \mathrm{mM})$ was prepared for the synthesis of AuNPs. In particular, a solution of the E. prostrata leaves extract $(40 \mathrm{~mL})$ was added to a solution of $\mathrm{HAuCl} 4(60 \mathrm{~mL}, 1.0 \mathrm{mM})$. The stirred solution was incubated at room temperature. The resulting solution showed a color change from light brown to dark brown within $30 \mathrm{~min}$ [28].

\subsection{Characterization of Synthesized AuNPs}

The formation and stability of AuNPs in aqueous solutions were initially characterized by UV-visible (Shimadzu UV-1650, Shimadzu, Kyoto, Japan) spectrophotometer in a wavelength range from 200-800 nm. FTIR spectra were recorded at room temperature on a spectrophotometer (PerkinElmer, Waltham, MA, USA). The AuNPs were dried at $60^{\circ} \mathrm{C}$ for $4 \mathrm{~h}$ and mixed with $\mathrm{KBr}$ to form a round disk suitable for FTIR measurements. The structural characterization and the crystalline nature of AuNPs were determined by X-ray diffractometer (diffractometer with Philips ${ }^{\circledR}$ PW 1830 X-ray generator, Philips, Amsterdam, The Netherlands) operating at a voltage of $40 \mathrm{kV}$ and current of $20 \mathrm{~mA}$ with $\mathrm{Cu}$ Ka radiation $\left(\lambda \frac{1}{4} 0.1542 \mathrm{~nm}\right)$ for the freeze-dried AuNPs. The surface morphology of AuNPs was investigated by Scanning Electron Microscopy (SEM), and the samples were prepared by placing a drop over a carbon coated grid and allowing drying before measurement on a Model JFC-1600 (JEOL USA, INC., Peabody, MA, USA). SEM instruments were operated at an accelerated voltage at $20 \mathrm{kV}$. The morphology of the nanoparticles was analyzed using the images obtained with a JEOL 3010 HRTEM with an accelerating voltage of $100 \mathrm{kV}$. A thin film of the sample was prepared on a carbon-coated copper grid by dropping a tiny amount of the sample on the grid and drying it under a lamp. A Malvern Zetasizer Nano ZS (Malvern Instruments Ltd., London, UK) Merck 2423 instrument was used to measure the zeta potential.

\subsection{Antibacterial Activity}

The bactericidal activity of AuNPs was tested by the well diffusion method against the pathogenic bacteria Escherichia coli (MTCC 1665), Staphylococcus aureus (MTCC 3160), and Bacilus subtilis (MTCC 441). Briefly, the individual bacterial strain was swabbed on three axes with a sterile cotton-tipped swab that was first dipped in the freshly prepared diluted culture. Approximately the same amount of bacterial cultures of both the strains was spread over Petri plate to create a confluent lawn of bacterial growth. A $7 \mathrm{~mm}$ diameter well was made on the MHA plate. The cultures were swabbed on test media with a sterile cotton swab. About $25 \mu \mathrm{L}$ of synthesized particles were inoculated to the well, and then the plates were incubated at $37^{\circ} \mathrm{C}$ for $24 \mathrm{~h}$. Tetracycline was used as a positive control $(30 \mathrm{mcg} / \mu \mathrm{L})$. All experiments were conducted in triplicate, and the results were concurrent [29]. 


\subsection{Evaluation of Total Antioxidant Activity}

The total antioxidant activities of the synthesized AuNPs and aqueous leaves extract were analyzed. First $0.1 \mathrm{gm}$ of the synthesized AuNPs and aqueous leaves extract were taken into a reaction vial at different concentrations $(100-500 \mu \mathrm{g} / \mathrm{mL}$ ) and mixed with $0.05 \%$ DMSO. Then $0.1 \mathrm{~mL}$ aliquot of the sample was mixed with $1 \mathrm{~mL}$ of the reagent solution $(0.6 \mathrm{M}$ sulfuric acid, $28 \mathrm{mM}$ sodium phosphate, and $4 \mathrm{mM}$ ammonium molybdate). The tubes were capped and then incubated at $95^{\circ} \mathrm{C}$ for $90 \mathrm{~min}$. The samples were cooled to $25^{\circ} \mathrm{C}$, and the absorbance was measured at $695 \mathrm{~nm}$ against a blank. The blank contained $1 \mathrm{~mL}$ of the reagent solution without the samples. The total antioxidant activity was expressed as the absorbance of samples. The higher the absorbance value, the higher the antioxidant activity. Ascorbic acid was also assayed for comparison [30].

\subsection{Determination of DPPH Radical Scavenging Activity}

AuNPs were screened for DPPH free radical scavenging activity by the method described by Chang et al. [31] with little modification. Briefly, $0.5 \mathrm{~mL}$ of $1.5 \mathrm{~m} \mathrm{MDPPH}$ was mixed with different concentrations $(31-1000 \mathrm{mg} / \mathrm{mL}$ ) of gold nanoparticles and incubated in dark for $30 \mathrm{~min}$. After incubation, the absorbance of the samples was determined by UV spectrophotometer (Shimadzu UV-1650, Shimadzu, Kyoto, Japan) at $517 \mathrm{~nm}$. DPPH methanol reagent without sample was used as a control, and Vitamin C was used as a standard.

\subsection{Cytotoxicity Study of Hep-G2 Cell Line}

To evaluate the cytotoxicity of aqueous leaf extract of E. prostrata and AuNPs, Hep-G2 cells were collected in the exponential phase of growth, seeded into 96-well tissue culture plates (15,000 per well), and allowed to adhere for $24 \mathrm{~h}$. Then, 1, 10, 100, 250, and $500 \mu \mathrm{g} / \mathrm{mL}$ concentrations of aqueous leaf extract of E. prostrata and AuNPs were added to the desired wells and incubated for $48 \mathrm{~h}$. After incubation, $20 \mu \mathrm{L}$ of an EMEM medium containing MTT (3-[4,5-dimethylthiazol-2-yl]-2,5diphenyltetrazolium bromide) $(5 \mathrm{mg} / \mathrm{mL})$ was added to each well and incubated at $37^{\circ} \mathrm{C}$ for $4 \mathrm{~h}$. Subsequently, the medium was changed with $100 \mu \mathrm{L}$ of DMSO, and optical densities were measured at $570 \mathrm{~nm}$. All the measurements were made in triplicate and expressed as the mean \pm standard error (Mosmann [32] and Kang et al. [33]).

\subsection{Statistical Analysis}

All experiments were carried out in triplicate and data were analyzed. For the experiments of antimicrobial activity, arithmetic mean values were considered for data analysis. All the statistical analysis was done by SPSS Statistics 18 Release Version 18.0.0, 2009 (BM Corporation, Armonk, NY, USA).

\section{Results and Discussion}

\subsection{Visual Observations and UV-Vis Spectroscopy}

The UV-visible spectral analysis confirmed the formation and stability of the biosynthesized AuNPs using the leaves extract of E. prostrata. At $534 \mathrm{~nm}$ wavelength, the optimum AuNPs production was determined at $60{ }^{\circ} \mathrm{C}, \mathrm{pH} 7$ with $1 \mathrm{mM} \mathrm{HAuCl}_{4}$, and 45 min incubation period (Figure 1). Reduction of $\mathrm{AuCl}_{4}{ }^{-}$was visually evident from the color change and the synthesis process completed within $90 \mathrm{~min}$, with a stable ruby-red color indicating the formation of AuNPs. A peak observed in the UV-visible spectrum corresponding to the SPR occurs at $534 \mathrm{~nm}$ and clearly showed the formation of AuNPs in solution as the exact position of absorbance depends on some factors such as the dielectric constants of the medium and size of the particle. It was observed that the crystalline shape of the biosynthesized AuNPs was dependent on the quantity of $\mathrm{Au}^{+}$ions in solution and the biomolecules or factors from the leaf extract of E. prostrata. 


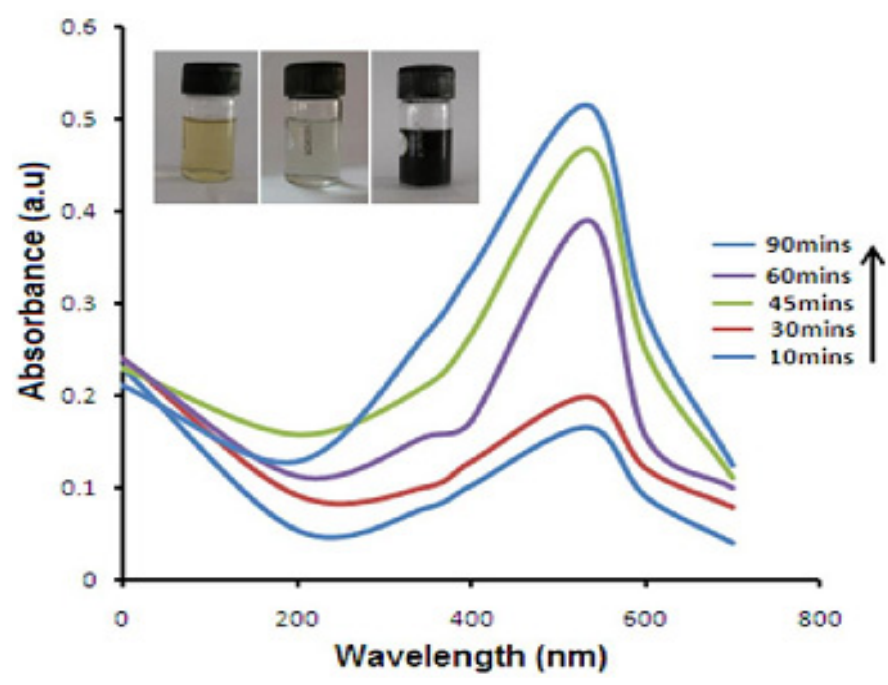

Figure 1. UV-vis spectral analysis and color intensity of biosynthesized NPs at various time intervals of AuNPs (gold nanoparticles) at $45 \mathrm{~min}$. The inset shows the color change from ruby-red to dark black color.

\subsection{X-Ray Diffraction (XRD) Analysis}

XRD performed the structural analysis of AuNPs prepared from the alkaline-treated sample. The XRD pattern of synthesized AuNPs showed pure crystalline gold nature (Figure 2). Reflection peaks appeared at $38.10^{\circ}, 44.13^{\circ}, 64.43^{\circ}$, and $77.32^{\circ}$ which correspond to (111), (200), (220), and (311) Miller indices, respectively. Taking into account the angular positions of the Bragg peaks, the face-centered cubic (FCC) structure was assigned to the gold nanostructures. The majority of the gold nanostructured samples were preferentially oriented along the (111) plane. Another less intense, board peak was observed, oriented along the (200) plane. The observed 'd-values' of the samples (from XRD patterns) correlate well with the standard 'd-values' from the JCPDS data card 04-0784 for Au and confirming the formation of AuNPs. The characteristic of FCC structure and the broadening of peaks confirmed the formation of NPs. The Scherrer equation was used to calculate average particle size and the size was found to be $28 \pm 1.5 \mathrm{~nm}$. Similar results were observed by Noruzi et al. [34], who reported that the XRD pattern was crystalline in nature and noted reflection peaks indicating the high purity of AuNPs synthesized by an aqueous extract of cypress leaves.

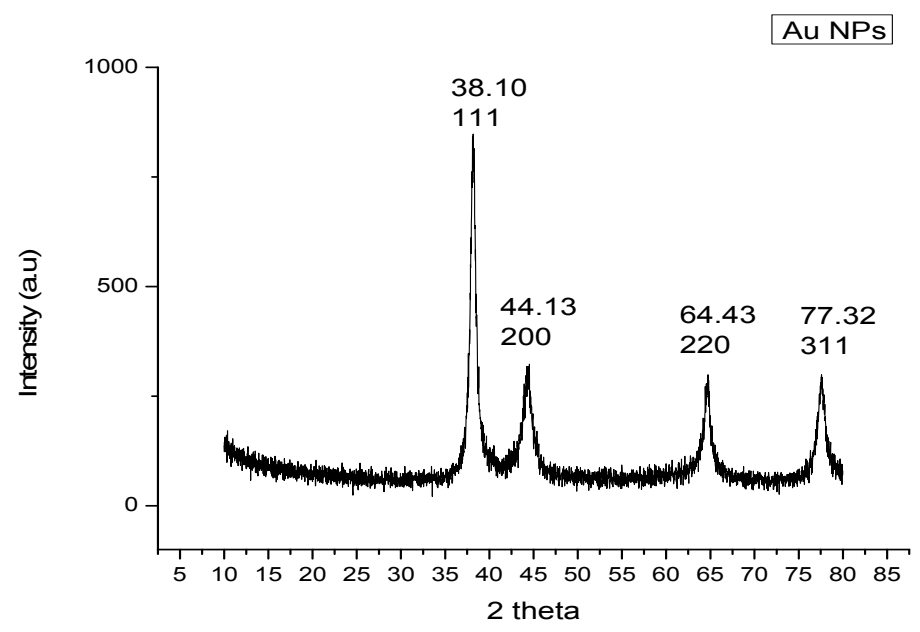

Figure 2. X-ray diffraction (XRD) patterns of biosynthesis of AuNPs using an aqueous extract of Eclipta prostrata. 


\subsection{FTIR Spectroscopy}

FTIR analysis showed the absorption peaks at 3351, 1671, 1405, 1038, and $597 \mathrm{~cm}^{-1}$ (Figure 3) for the synthesis of AuNPs. The absorption band at $3351 \mathrm{~cm}^{-1}$ for Hydroxy group, $\mathrm{H}$-bonded $\mathrm{OH}$ stretch, $1671 \mathrm{~cm}^{-1}$ for Amide [35], $1405 \mathrm{~cm}^{-1}$ which expose symmetric stretching of $\mathrm{COO}^{-}$from an amino group, $1038 \mathrm{~cm}^{-1}$ for Phosphate ion, and $597 \mathrm{~cm}^{-1}$ for Alcohol, OH out-of-plane bend.

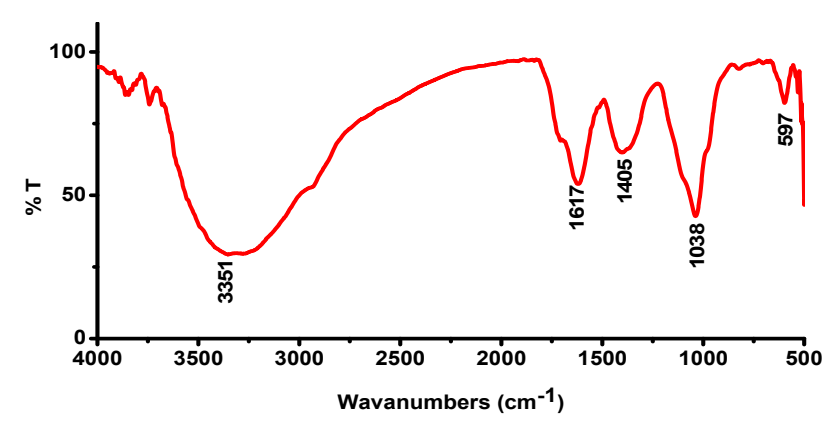

Figure 3. Fourier transform infrared spectroscopy (FTIR) analysis of synthesized AuNPs

The proposed reaction was $\mathrm{Au}^{+}$ions' reduction into metallic $\mathrm{Au}$ nanoparticles in the presence of metabolites and redox enzymes [36]. The significant reduction in reaction time with Eclipta leaf is an important result and will enable nanoparticle biosynthesis methods to compete with other plant-assisted biosynthesis routes for the formation of nanoparticles that are currently much more rapid and reproducible [37]. The IR band proved the presence of amines, alcohols, phenols, and aromatic groups and strongly suggested the presence of certain proteins in Eclipta prostrata that act as reducing/capping agents and may be responsible for the synthesis of AuNPs using leaves of E. prostrata.

\subsection{SEM-EDX Analysis}

The SEM analysis clearly showed the presence of the synthesized AuNPs. NPs ranging from 25 to $40 \mathrm{~nm}$ with an average size of $32 \pm 1.1$ were observed in the surface morphology of AuNPs. It was noted that smaller sized particles were almost spherical in shape, and some of them were aggregated (Figure 4a). Similar results were found in Kumar et al. [38]: the SEM micrographs showed aggregates of Zingiber officinale synthesized AuNPs, and the particles were in the range of 15-25 nm and are not in direct contact even within the aggregates, indicating the stabilization of NPs by the capping agents. The EDX analysis shown in Figure $4 \mathrm{~b}$ revealed that a strong signal of Au peak was observed at approximately $3.6 \mathrm{keV}$, which is typical for the absorption of metallic gold nanocrystallites due to SPR.
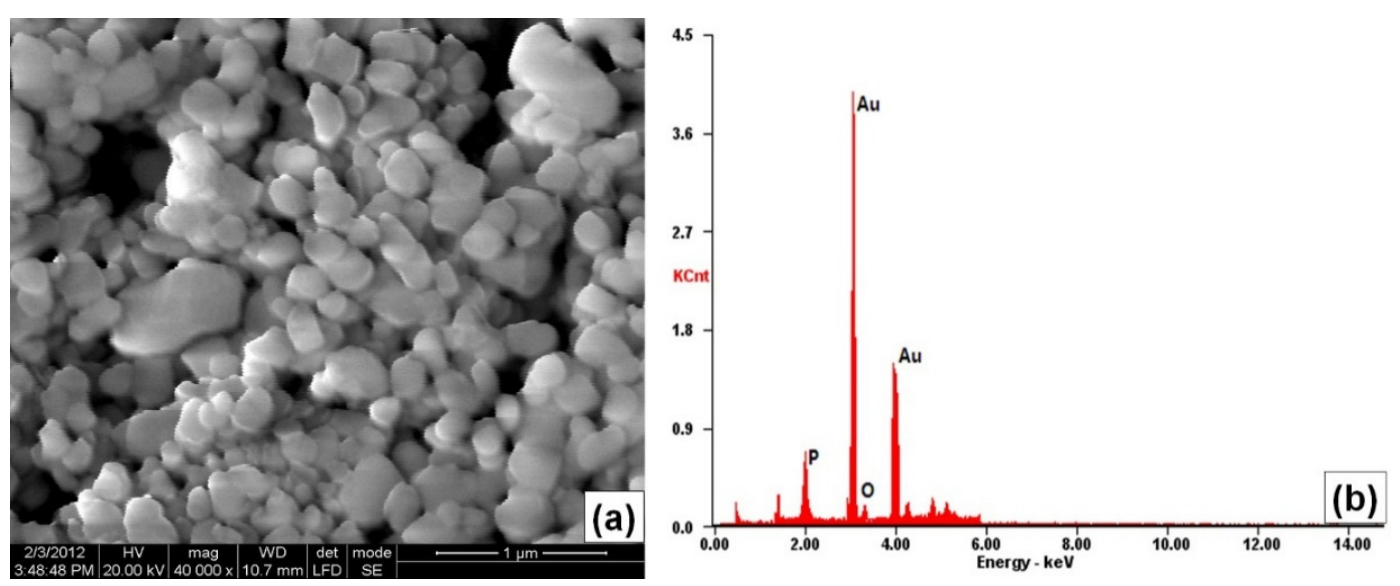

Figure 4. (a) Scanning electron microscope (SEM) micrograph showed the synthesized of AuNPs using E. prostrata leaf aqueous extract $(\times 40,000)$ and $($ b) EDX analysis showing the chemical composition of synthesized AuNPs. 


\subsection{HRTEM Analysis and SAED Pattern}

The morphology and size of the particles were determined by the HRTEM images shown in Figure 5a. The particles formed were spherical, hexagonal, and triangular in shape. The NPs formed were in the range of 23 to $46 \mathrm{~nm}$ with an average size of $31 \pm 1.6 \mathrm{~nm}$. The SAED of a single spherical particle confirmed the crystalline nature of AuNPs and the rings corresponding to (111), (200) and (220) planes of FCC crystalline lattices of gold (Figure 5b). The reflection patterns indicated that the surfaces of the gold plates were flat and crystalline in nature. Similar results were found in AuNPs synthesized using ethonolic leaf extract of Bacopa monnieri: they were predominantly spherical in shape with a size distribution range of 3-45 $\mathrm{nm}$ [39].
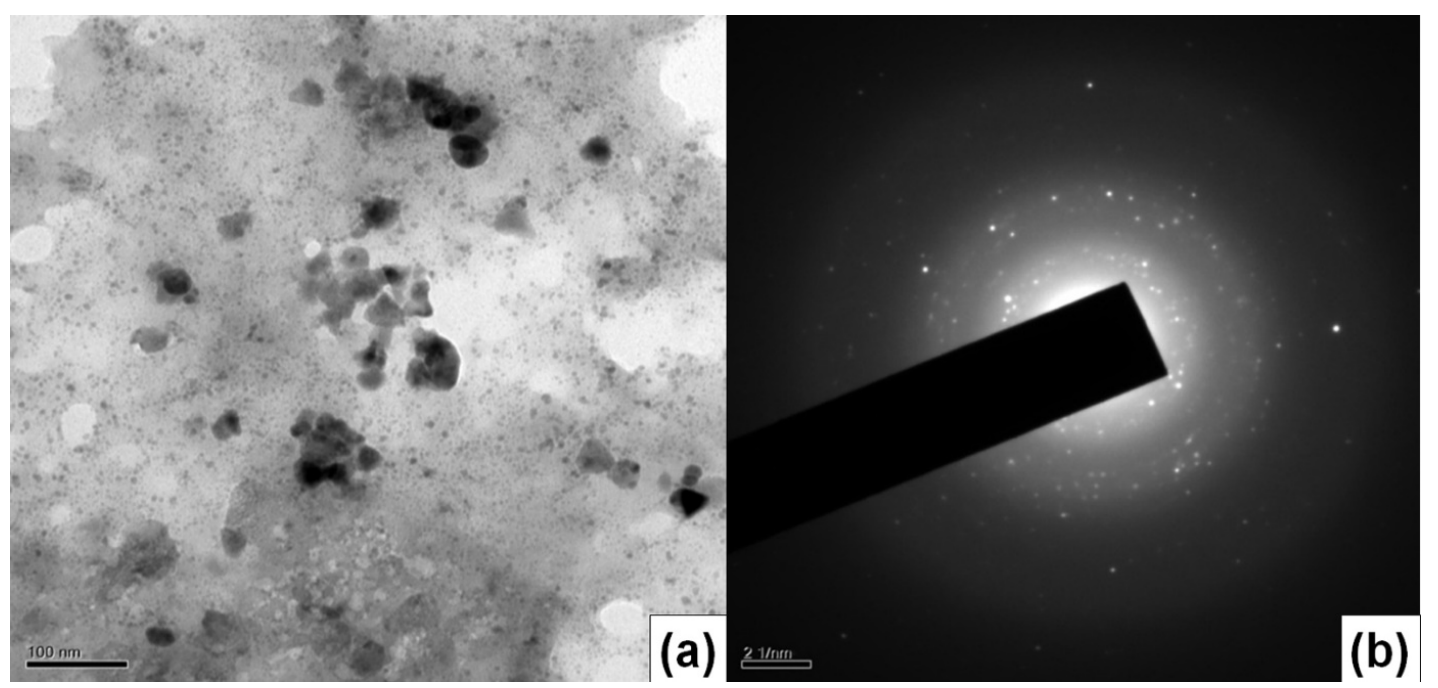

Figure 5. (a) High-resolution transmission electron microscopy (HRTEM) micrograph of synthesized AuNPs; (b) selected area of electron diffraction pattern (SAED) of the synthesized AuNPs showing the rings.

\subsection{Zeta Potential Analysis}

Zeta potential (ZP) values reveal information regarding the surface charge and stability of biosynthesized AuNPs. As can be seen from Figure 6, the average ZP value of $-17.4 \mathrm{mV}$ indicated that the capping molecules present on the surface of AuNPs are mainly comprised of negatively charged groups and also responsible for moderate stability of the nanoparticles. The sample did not precipitate for a period of one month, indicating that the AuNPs are stable for a reasonable period of time. Many reports have proposed that surface-active molecules can stabilize the nanoparticles and a reaction of the metal ions is possibly facilitated by reducing sugars and/or terpenoids.

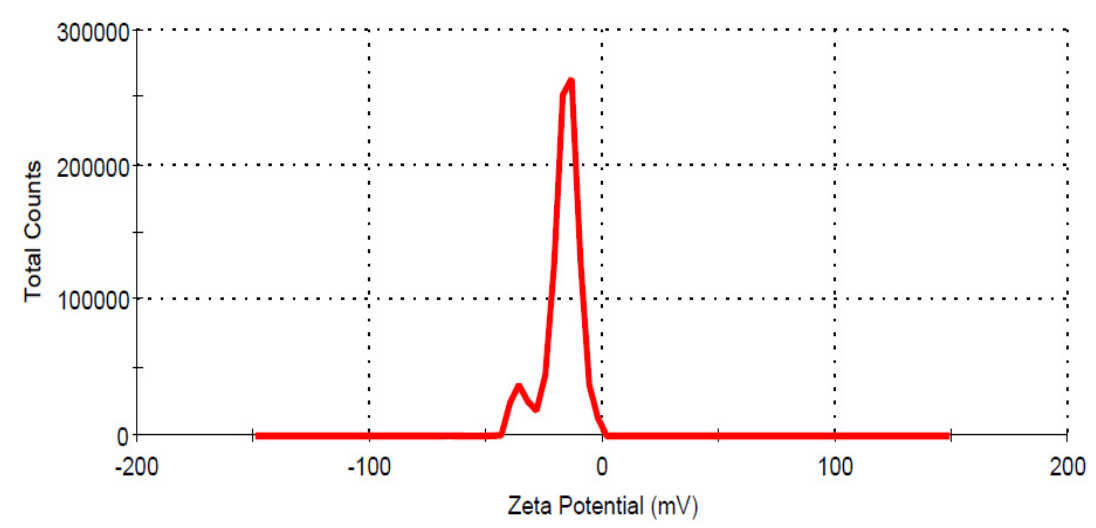

Figure 6. Stability of AuNPs at $-17.4 \mathrm{mV}$ in zeta potential analysis. 


\subsection{Calculation of Average Number of Gold Atoms per Nanoparticle}

The average number of gold atoms per nanoparticle may be calculated from high-resolution TEM analysis [40]. The HRTEM images of the synthesized gold nanoparticles shows the average particle size of about $31 \pm 1.6 \mathrm{~nm}(D, \mathrm{~nm})$. Assuming a spherical shape and a uniform FCC structure [41], the average number of gold atoms $(N)$ for each type of nanosphere was calculated by the following equation, where $\rho$ is the density for FCC gold $\left(19.3 \mathrm{~g} / \mathrm{cm}^{3}\right)[42,43]$ and M stands for atomic weight of gold $(197 \mathrm{~g} / \mathrm{mol})$ :

$$
N=\frac{\pi}{6} \frac{\rho D^{3}}{\mathrm{M}}=30.89602 D^{3},
$$

On applying the above equation, the average number of gold atoms per synthesized nanoparticle was found to be in the range from $885,251.797$ to $1,070,422.767$ atoms.

\subsection{Antibacterial Activity}

The antibacterial activity of the AuNPs was studied against gram-positive (B. substilis and $S$. aureus) and gram-negative (E. coli) using the well diffusion method (Figure 7). The highest antibacterial activity was observed against E. coli $(24 \pm 0.67 \mathrm{~nm})$, followed in order by $S$. aureus $(16 \pm 0.91 \mathrm{~nm})$ and B. substilis $(12 \pm 0.13 \mathrm{~nm})$. However, a leaf extract of E. prostrata did not show any significant antibacterial activity, whereas the AuNPs showed maximum bactericidal activity. AuNPs possess well-developed surface chemistry, chemical stability, and a large surface-to-volume ratio, due to which more drug molecules get adsorbed on their surfaces via electrostatic attraction between the amino group of drugs and nanoparticles. The gold nanoparticles surrounded by some drug moieties now act as a single group against the microbial organisms, thereby increasing the microbial activity [44]. AuNPs may initially get anchored to bacterial cell wall and interact with the peptidoglycan layer, thereby causing the breakage of bonds and entering inside the cell to cause perforations at the exterior [45]. This result reveals that the AuNPs synthesized here have effective antibacterial activity, and they contribute the most to the antibacterial capability of AuNPs.

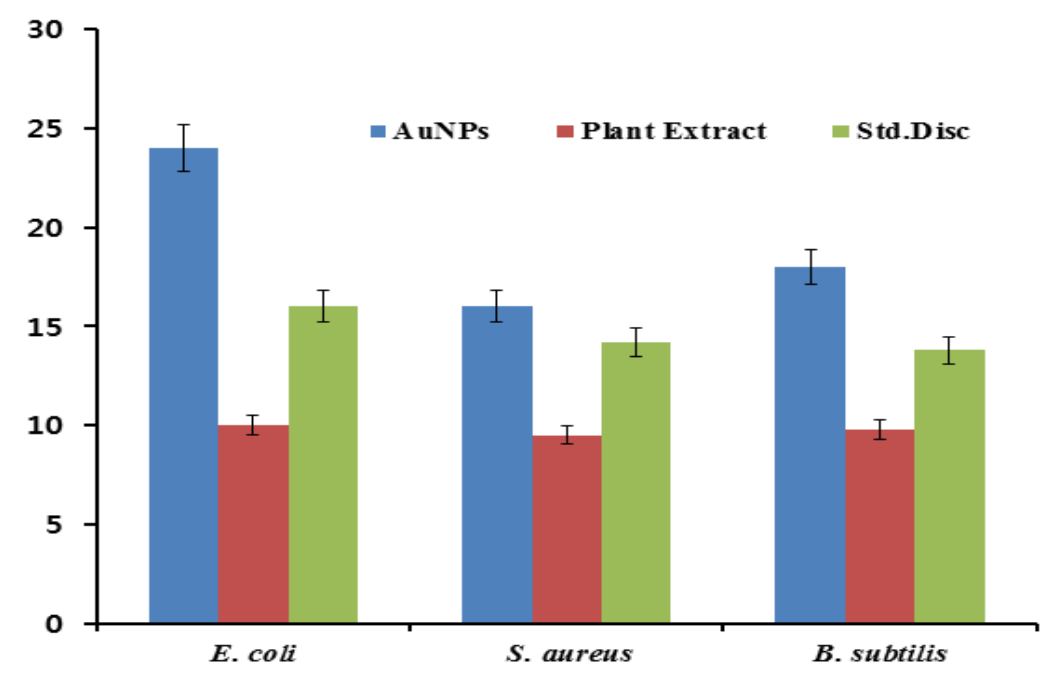

Figure 7. Antibacterial activity of AuNPs against human pathogens.

\subsection{Evaluation of Total Antioxidant Activity}

Using an aqueous leaf extract of E. prostrata, the total antioxidant activity was found to be high in synthesized NPs at different concentrations between 100 and $500 \mu \mathrm{g} / \mathrm{mL}$. The aqueous leaf extract of E. prostrata showed $0.67 \pm 0.78 \mathrm{mg}$ gallic acid equivalent $/ \mathrm{g}(\mathrm{mg} \mathrm{GAE} / \mathrm{g})$ and for standard ascorbic acid $0.75 \pm 0.84 \mathrm{mg}$ GAE$/ \mathrm{g}$ followed by AuNPs $0.91 \pm 0.24 \mathrm{mg} \mathrm{GAE} / \mathrm{g}$, at the concentration of $500 \mu \mathrm{g} / \mathrm{mL}$ respectively (Figure 8a). 


\subsection{Determination of DPPH Radical Scavenging Activity}

To assess the antioxidant activity of E. prostrata extract and as synthesized AuNPs, DPPH was used as a free radical model and treated with varying concentrations $(100-500 \mu \mathrm{g} / \mathrm{mL})$ of E. prostrata extract and AuNPs. The percentage of inhibition of DPPH radical scavenging activity is presented in Figure 8b. The average percentage inhibition of synthesized AuNPs (63\%) and powdered leaves of E. prostrata was $48 \%$, and control of ascorbic acid showed $95 \%$ in $500 \mu \mathrm{g} / \mathrm{mL}$ concentration. The AuNPs coated with torolex and chitosan enhance the DPPH radical scavenging activity [46].
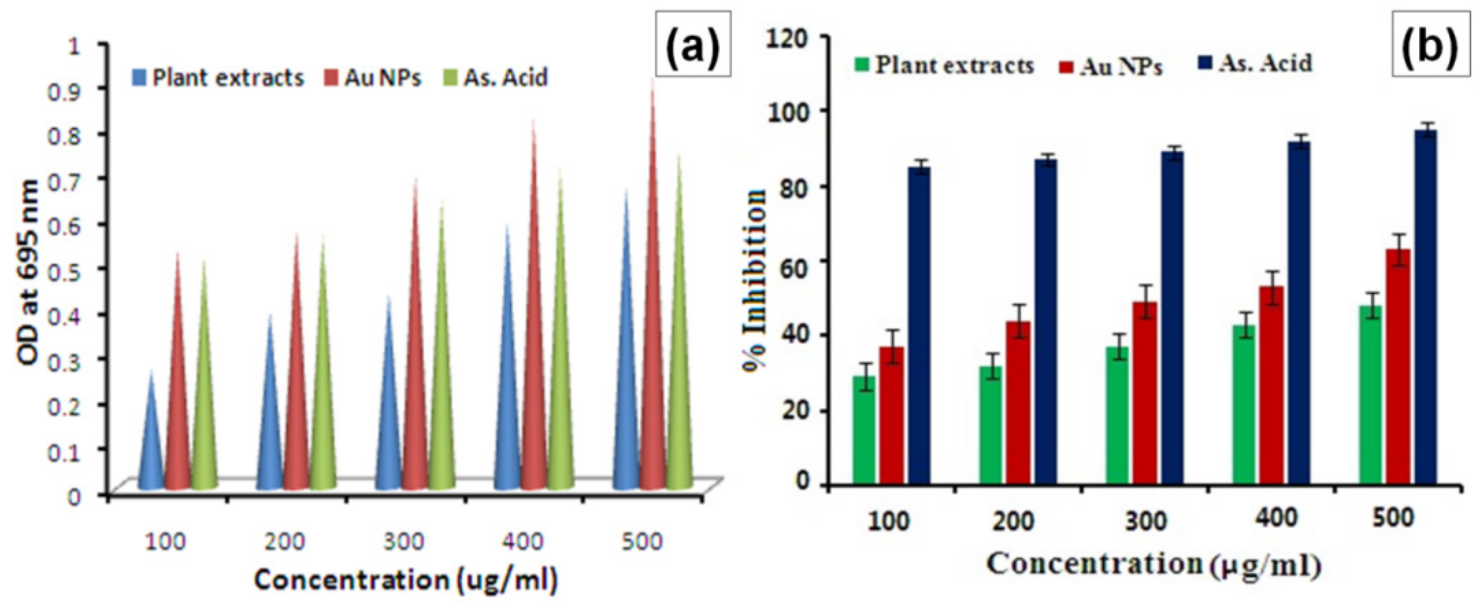

Figure 8. (a) Total antioxidant assay of synthesized AuNPs and (b) DPPH assay of synthesized AuNPs.

\subsection{Cytotoxicity Study of Hep-G2 Cell Line}

The aqueous leaf extract of E. prostrata and synthesized AuNPs were tested at 1-500 $\mu \mathrm{g} / \mathrm{mL}$, which provided cellular toxicity of $7.5 \%, 12 \%, 22 \%, 32 \%$, and $39 \%$ for the aqueous leaf extract of $E$. prostrata and for synthesized AuNPs $16 \%, 28 \%, 40 \%, 57 \%$, and $69 \%$, respectively. The plaque formations of the Hep-G2 cell lines were found to induce cytopathic effects and necrosis formation. The viability was in inverse proportion to the cellular regeneration of Hep-G2 (Figure 9a-f). The results of this study suggest that the cytotoxicity of biologically synthesized AuNPs increased with the increasing concentration of nanoparticles. AuNPs of certain non-irregular shapes can be adsorbed readily to the surface of the biomolecules, which show higher surface plasmon resonance and will have a greater contrast effect than those of photothermal dyes that are used regularly in the detection of cancer cell lines $[47,48]$. In Figure 10, it is also quite clear that the test samples showed concentration-dependent cytotoxic effect on cancerous cells. This observation is comparable with the report published by Milovanovic et al. on gold(III)-monoethylenediamine complexes on chronic lymphocytic leukemia (CLL) cells [49]. From the results of biological analysis, it is established that our AuNPs are possible candidates for use in nanotherapy. AuNPs possess good cytotoxicity properties and biocompatibility. 

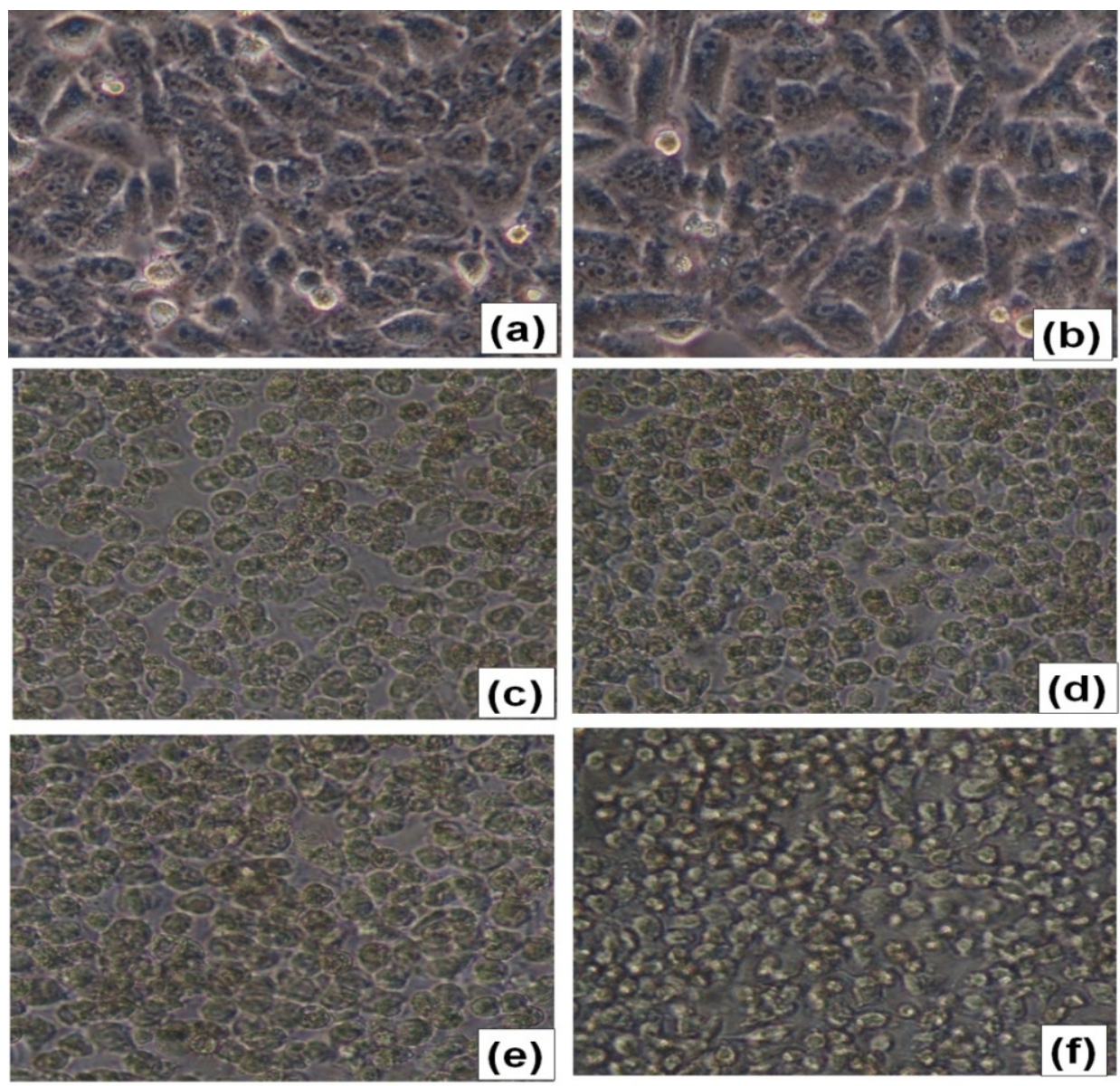

Figure 9. Cytotoxic effect of synthesized AuNPs against Hep-G2 cancer cell line showed cell toxicity (\%) at different concentrations: (a) Control; (b) $1 \mu \mathrm{g} / \mathrm{mL}$; (c) $10 \mathrm{~g} / \mathrm{mL}$; (d) $100 \mu \mathrm{g} / \mathrm{mL}$; (e) $250 \mu \mathrm{g} / \mathrm{mL}$; and (f) $500 \mu \mathrm{g} / \mathrm{mL}$.

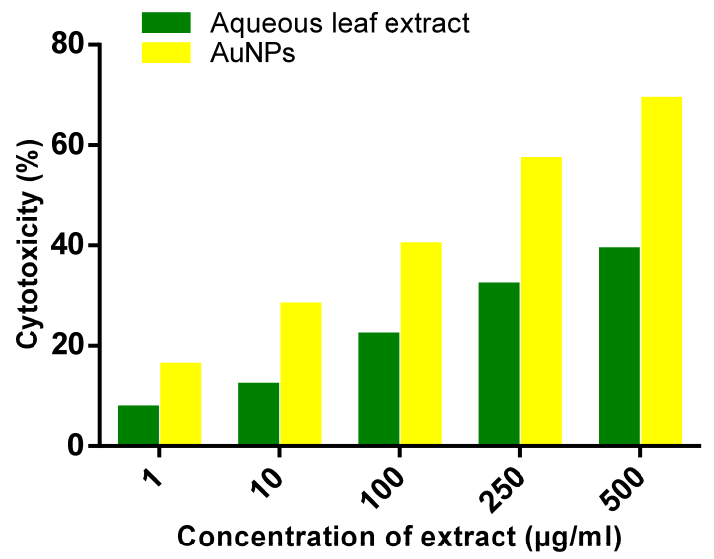

Figure 10. Anticancer activity of aqueous leaf extract of E. prostrata and AuNPs on a Hep-G2 cancer cell line.

\section{Conclusions}

In the present study, a green synthesis approach using the leaf extract of E. prostrata was successful for preparing functionally stable and crystalline AuNPs. This method is easy, efficient, and eco-friendly, and is the best option for metal. 
Nanoparticles synthesis was compared to other methods. The prepared nanoparticles were characterized to confirm their formation using UV-vis, XRD, FTIR, SEM, HRTEM, and EDAX analysis. From the UV-visible spectrum, the absorbance at $534 \mathrm{~nm}$ confirms the presence of AuNPs. The XRD pattern reveals that the prepared AuNPs have a face-centered cubic structure with $2 \theta$ values at $38.10^{\circ}, 44.13^{\circ}, 64.43^{\circ}$, and $77.32^{\circ}$. FTIR spectrum results confirmed the presence of AuNPs with the phytochemicals that are responsible for their conversion. Zeta potential (ZP) values $(-17.4 \mathrm{mV})$ showed a negative charge density with moderate stability of the synthesized nanoparticles. The HRTEM images showed spherical, hexagonal, and triangular morphology with an average size of $31 \pm 1.6 \mathrm{~nm}$, and the biomedical evaluation proved that the synthesized AuNPs are biocompatible.

Acknowledgments: This paper was supported by the KU-Research Professor Program of Konkuk University, Seoul, South Korea.

Author Contributions: Govindasamy Rajakumar executed the lab work and prepared the manuscript draft. Thandapani Gomathi, Govindarasu Mydhili, Seung-Hyun Kim, Tak-Jun Lee and Muthu Thiruvengadam co-participated in the research execution. Abdul Abdul Rahuman designed and supervised the study and helped revise the manuscript. II-Min Chung prepared and proofread the final version of the manuscript.

Conflicts of Interest: The authors declare no conflict of interest.

\section{References}

1. Lee, K.D.; Nagajyothi, P.C.; Sreekanth, T.V.M.; Park, S. Eco-friendly synthesis of gold nanoparticles (AuNPs) using Inonotus obliquus and their antibacterial, antioxidant and cytotoxic activities. J. Ind. Eng. Chem. 2015, 26, 67-72. [CrossRef]

2. Islam, N.U.; Jalil, K.; Shahid, M.; Rauf, A.; Muhammad, N.; Khan, A.; Shah, M.R.; Khan, M.A. Green synthesis and biological activities of gold nanoparticles functionalized with Salix alba. Arab. J. Chem. 2015. [CrossRef]

3. Muthukumar, T.; Sambandam, B.; Aravinthan, A.; Sastry, T.P.; Kim, J.H. Green synthesis of gold nanoparticles and their enhanced synergistic antitumor activity using HepG2 and MCF7 cells and its antibacterial effects. Process. Biochem. 2016, 51, 384-391. [CrossRef]

4. Nakkala, J.R.; Mata, R.; Sadras, S.R. The antioxidant and catalytic activities of green synthesized gold nanoparticles from Piper longum fruit extract. Process. Saf. Environ. 2016, 100, 288-294. [CrossRef]

5. Ansari, S.H.; Islam, F.; Sameem, M. Influence of nanotechnology on herbal drugs. J. Adv. Pharm. Technol. Res. 2012, 3, 142-146. [CrossRef] [PubMed]

6. Mishra, P.; Ray, S.; Sinha, S.; Das, B.; Khan, Md.I.; Behera, S.K.; Yun, S.I.; Tripathy, S.K.; Mishra, A. Facile bio-synthesis of gold nanoparticles by using extract of Hibiscus sabdariffa and evaluation of its cytotoxicity against U87 glioblastoma cells under hyperglycemic condition. Biochem. Eng. J. 2016, 105, 264-272. [CrossRef]

7. Ghosh, S.; Patil, S.; Ahire, M.; Kitture, R.; Gurav, D.D.; Jabgunde, A.M.; Kale, S.; Pardesi, K.; Shinde, V.; Bellare, J.; et al. Gnidia glauca flower extract mediated synthesis of gold nanoparticles and evaluation of its chemocatalytic potential. J. Nanobiotechnol. 2012, 10, 17. [CrossRef] [PubMed]

8. Ozols, R.F.; Herbst, R.S.; Colson, Y.L.; Gralow, J.; Bonner, J.; Curran, W.J., Jr.; Eisenberg, B.L.; Ganz, P.A.; Kramer, B.S.; Kris, M.G.; et al. Clinical cancer advances 2006: major research advances in cancer treatment, prevention, and screening-A report from the American Society of Clinical Oncology. J. Clinic. Oncol. 2007, 25, 146-162. [CrossRef] [PubMed]

9. Parida, U.K.; Bindhani, B.K.; Nayak, P. Green Synthesis and Characterization of Gold Nanoparticles Using Onion (Allium cepa) Extract. World J. Nanoscience. Eng. 2011, 1, 93-98. [CrossRef]

10. Selim, M.E.; Hend, A.A. Gold nanoparticles induce apoptosis in MCF-7 human breast cancer cells. Asian Pac. J. Cancer Prev. 2012, 13, 1617-1620. [CrossRef] [PubMed]

11. Velmurugan, P.; Shim, J.; Bang, K.S.; Oh, B.T. Gold nanoparticles mediated coloring of fabrics and leather for antibacterial activity. J. Photochem. Photobiol. B Biol. 2016, 160, 102-109. [CrossRef] [PubMed]

12. Dhamecha, D.; Jalalpure, S.; Jadhav, K. Nepenthes khasiana mediated synthesis of stabilized gold nanoparticles: Characterization and biocompatibility studies. J. Photochem. Photobiol. B 2016, 154, 108-117. [CrossRef] [PubMed]

13. Singh, P.; Kim, Y.J.; Yang, D.C. A strategic approach for rapid synthesis of gold and silver nanoparticles by Panax ginseng leaves. Artif. Cells Nanomed. Biotechnol. 2015, 24, 1-9. 
14. Klekotko, M.; Matczyszyn, K.; Siednienko, J.; Olesiak-Banska, J.; Pawlik, K.; Samoc, M. Bio-mediated synthesis, characterization and cytotoxicity of gold nanoparticles. Phys. Chem. Chem. Phys. 2015, 7, 29014-29019. [CrossRef] [PubMed]

15. Yallappa, S.; Manjanna, J.; Dhananjaya, B.L.; Vishwanatha, U.; Ravishankar, B.; Gururaj, H. Pytosynthesis of gold nanoparticles using Mappia foetida leaves extract and their conjugation with folic acid for delivery of doxorubicin to cancer cells. J. Mater. Sci. Mater. Med. 2015, 26, 235. [CrossRef] [PubMed]

16. Jia, J.L.; Xu, H.H.; Zhu, L.; Ye, W.H.; Li, D.Q. Biosynthesis of Gold Nanoparticles Using Novel Bamboo (Bambusa chungii) Leaf Extracts. J. Nanosci. Nanotechnol. 2015, 5, 674-677. [CrossRef]

17. Sneha, K.; Yn, L.S.; Yeoung-Sang, Y. Optimization Studies of Conditions for Biological Synthesis of AuNPs in Various Shapes Using Plant Extract (Ocimum sanctum). J. Nanosci. Nanotechnol. 2015, 5, 326-329. [CrossRef]

18. Patra, S.; Mukherjee, S.; Barui, A.K.; Ganguly, A.; Sreedhar, B.; Patra, C.R. Green synthesis, characterization of gold and silver nanoparticles and their potential application for cancer therapeutics. Mater. Sci. Eng. C Mater. Biol. Appl. 2015, 53, 298-309. [CrossRef] [PubMed]

19. Ying, D.L. The research progress in chemical constituents, pharmacological effects and clinic application of Eclipta prostrata. China Pharm. 2008, 19, 2876-2878.

20. Xi, F.M.; Li, C.T.; Mi, J.L.; Wu, Z.J.; Chen, W.S. Three new olean-type triterpenoid saponins from aerial parts of Eclipta prostrata (L.). Nat. Prod. Res. 2014, 28, 35. [CrossRef] [PubMed]

21. Yahara, S.; Ding, N.; Nohara, T.; Masuda, K.; Ageta, H. Taraxastane glycosides from Eclipta alba. Phytochemistry 1997, 44, 131-135. [CrossRef]

22. Abdel-Kader, M.S.; Bahler, B.D.; Malone, S.; Werkhoven, M.C.; van Troon, F.; David, X.; Wisse, J.H.; Bursuker, I.; Neddermann, K.M.; Mamber, S.W.; Kingston, D.G. DNA-damaging steroidal alkaloids from Eclipta alba from the suriname rainforest. J. Nat. Prod. 1998, 61, 1202-1208. [CrossRef] [PubMed]

23. Santhosh, K.C.; Govindasamy, S.; Sukumar, E. Lipid lowering activity of Eclipta prostrata in experimental hyperlipidemia. J. Ethnopharmacol. 2006, 105, 332-335.

24. Editorial Committee of Chinese Pharmacopoeia. Chinese Pharmacopoeia, 9th ed.; Chemical Industry Press: Beijing, China, 2010; Volume 1, p. 352.

25. Mukunthan, K.; Balaji, S. Cashew apple juice (Anacardium occidentale L.) speeds up the synthesis of silver nanoparticles. Int. J. Green Nanotechnol. 2012, 4, 71-79. [CrossRef]

26. Kumar, V.; Yadav, S.K. Plant-mediated synthesis of silver and gold nanoparticles and their applications. J. Chem. Technol. Biotechnol. 2009, 84, 151-157. [CrossRef]

27. Minjas, J.N.; Sarda, R.K. Laboratory observations on the toxicity of Swartzia madagascariensis (Leguminosae) extract to mosquito larvae. Trans. R. Soc. Trop. Med. Hyg. 1986, 80, 460-461. [CrossRef]

28. Daisy, P.; Saipriya, K. Biochemical analyses of Cassia fistula aqueous extract and phytochemically synthesized gold nanoparticles as hypoglycemic treatment for diabetes mellitus. Int. J. Nanomed. 2012, 7, 1189-1202. [CrossRef] [PubMed]

29. Kora, A.J.; Manjusha, R.; Arunachalam, J. Superior bactericidal activity of SDS capped silver nanoparticles: Synthesis and characterization. Mater. Sci. Eng. C. 2009, 29, 2104-2109. [CrossRef]

30. Prieto, P.; Pineda, M.; Aguilar, M. Spectrophotometric quantitation of antioxidant capacity through the formation of a phosphomolybdenum complex: Specific application to the determination of vitamin E. Anal. Biochem. 1999, 269, 337-341. [CrossRef] [PubMed]

31. Chang, C.C.; Yang, M.H.; Wen, H.M.; Chern, J.C. Estimation of total flavonoid content in propolis by two complementary colorimetric methods. J. Food Drug Anal. 2002, 10, 178-182.

32. Mosmann, T. Rapid colorimetric assay for cellular growth and survival: application to proliferation and cytotoxicity assays. J. Immunol. Methods 1983, 65, 55-63. [CrossRef]

33. Kang, Y.; Siegel, P.M.; Shu, W.; Drobnjak, M.; Kakonen, S.M.; Cordon-Cardo, C.; Guise, T.A.; Massague, J. A multigenic program mediating breast cancer metastasis to bone. Can. Cell. 2003, 3, 537-549. [CrossRef]

34. Noruzi, M.; Zare, D.; Davoodi, D. A rapid biosynthesis route for the preparation of gold nanoparticles by aqueous extract of cypress leaves at room temperature. Spectrochim. Acta. A Mol. Biomol. Spectrosc. 2012, 94, 84-88. [CrossRef] [PubMed]

35. Juszczak, L.J. Comparative Vibrational Spectroscopy of Intracellular Tau and Extracellular Collagen I Reveals Parallels of Gelation and Fibrillar Structure. J. Biol. Chem. 2004, 279, 7395-7404. [CrossRef] [PubMed]

36. Thakkar, K.N.; Mhatre, S.S.; Parikh, R.Y. Rasesh Biological synthesis of metallic nanoparticles. Nanomedicine 2010, 6, 257-262. 
37. Jha, A.K.; Prasad, K.; Prasad, K.; Kulkarni, A.R. Plant system: Nature's nanofactory. Coll. Surf. B Biointer. 2009, 73, 219-223. [CrossRef] [PubMed]

38. Kumar, K.P.; Paul, W.; Sharma, C.P. Green synthesis of gold nanoparticles with Zingiber officinale extract: Characterization and blood compatibility. Process. Biochem. 2011, 46, 2007-2013. [CrossRef]

39. Babu, P.J.; Sharma, P.; Saranya, S.; Bora, U. Synthesis of gold nanoparticles using ethonolic leaf extract of Bacopa monnieri and UV irradiation. Mat. Lett. 2013, 93, 431-434. [CrossRef]

40. Liu, X.; Atwater, M.; Wang, J.; Huo, Q. Extinction coefficient of gold nanoparticles with different sizes and different capping ligands. Collo. Surf. B Biointerfaces 2007, 58, 3-7. [CrossRef] [PubMed]

41. Mucic, R.C.; Storhoff, J.J.; Mirkin, C.A.; Letsinger, R.L. DNA-directed synthesis of binary nanoparticle network materials. J. Am. Chem. Soc. 1998, 120, 12674-12675. [CrossRef]

42. Zhang, H.; Hussain, I.; Brust, M.; Cooper, A.I. Emulsion-Templated Gold Beads Using Gold Nanoparticles as Building Blocks. Adv. Materials 2004, 16, 27-30. [CrossRef]

43. Cui, X.D.; Primak, A.; Zarate, X.; Tomfohr, J.; Sankey, O.F.; Moore, T.A.; Gust, D.; Nagahara, L.A.; Lindsay, S.M. Changes in the Electronic Properties of a Molecule When It Is Wired into a Circuit. J. Phys. Chem. B 2002, 106, 8609. [CrossRef]

44. Burygin, G.; Khlebtsov, B.; Shantrokha, A.; Dykman, L.; Bogatyrev, V.; Khlebtsov, N. On the enhanced antibacterial activity of antibiotics mixed with gold nanoparticles. Nanoscale Res. Lett. 2009, 4, 794-801. [CrossRef] [PubMed]

45. Parashar, U.K.; Kumar, V.; Bera, T.; Saxena, P.S.; Nath, G.; Srivastava, S.K.; Giri, R.; Srivastava, A. Study of mechanism of enhanced antibacterial activity by green synthesis of silver nanoparticles. Nanotechnology 2011, 22, 1-13. [CrossRef] [PubMed]

46. Raghunandan, D.; Bedre, M.D.; Basavaraja, S.; Sawle, B.; Manjunath, S.Y.; Venkataraman, A. Rapid biosynthesis of irregular shaped gold nanoparticles from macerated aqueous extracellular dried clove buds (Syzygium aromaticum) solution. Coll. Surf. B Biointerfaces 2010, 79, 235-240. [CrossRef] [PubMed]

47. Giljohann, D.A.; Seferos, D.S.; Daniel, W.L.; Massich, M.D.; Patel, P.C.; Mirkin, C.A. Gold nanoparticles for biology and medicine. Chem. Int. Ed. Engl. 2010, 49, 3280-3294. [CrossRef] [PubMed]

48. Katti, J. Nanocompatible chemistry toward fabrication of target-specific gold nanoparticles. Am. Chem. Soc. 2006, 128, 11342-11343.

49. Milovanović, M.; Djeković, A.; Volarević, V.; Petrović, B.; Arsenijević, N.; Bugarcić, Z.D. Ligand substitution reactions and cytotoxic properties of $[\mathrm{Au}(\mathrm{L}) \mathrm{Cl} 2](+)$ and [AuCl2(DMSO)2]+ complexes (L=ethylenediamine and S-methyl-1-cysteine). J. Inorg. Biochem. 2010, 104, 944-949. [CrossRef] [PubMed] 